\title{
EGES Preface
}

The E-Government and E-Services (EGES) Conference at WCC 2010 was a cooperation of a number of groups that already have well-established activities in the field of e-government, e-governance, e-business, etcetera. Notably IFIP working group 8.5 (Information Systems in Public Administration) IFIP working group 6.11 (Communication, Information and Security Aspects of E-Business, E-services and E-society) and the CSI SIG on E-Governance (Computer Society of India Special Interest Group on E-Governance) joined forces with the Program Co-chairs to make this stream of the IFIP World Computer Congress indeed outstanding and challenging. At this event, contributions with perspectives from researchers, practitioners and policymakers were presented. Looking at these three angles has led to new perspectives and a better understanding of the challenges and opportunities that come with developing and implementing e-government services and applications. With this new area of IT applications, there is a great need to share good practices across different parts of the world - the developed world and the emerging economies, the domains of government and business, and also to promote academic and research work to build the theoretical foundations for this field. This field has great potential to improve delivery of services from governments to citizens and interaction between different parts of government and public administration, between government and businesses, and of course between government and citizens. We hope this conference will be seen a step towards addressing the digital divide and rural-urban divide.

Twelve papers from seven countries, one invited speaker and a panel session addressed a wide spectrum of interesting topics, divided into five themes: interoperability, participation, adoption and diffusion, back end transformation and new applications. The number of papers was limited due to a strict reviewing process which ensured high-quality contributions. The acceptance rate for EGES 2010 was 33\%. We thank all contributors, the Program Committee members and all reviewers for their efforts and commitment. Without them EGES would not have happened.

We refrain from mentioning the details of the papers and from highlighting a few of them. They are all worth reading and therefore we encourage the reader to do just that. We would also like to mention the effort it takes to compile the proceedings, a valuable document that provides worthwhile reading and an archival document of the event. Similar to compiling a high-quality program, producing high-quality proceedings like the one you are reading now is a challenge. We thank the colleagues that took up this challenge and succeeded. 
As mentioned above, EGES 2010 was a co-operation between different working groups and specialist groups. E-government in all its aspects is a typical example of an interdisciplinary issue that deserves such co-operation. Let us continue with this.

September 2010

Marijn Janssen

Winfried Lamersdorf

Lalit Sawhney

Leon Strous 